\title{
ЛИНГВИСТИКА
}

\author{
А.К. Сабанчиева
}

\section{ОСОБЕННОСТИ ТЕРМИНОВ}

\author{
КАК СПЕЦИАЛЬНЫХ ЛЕКСИЧЕСКИХ ЕДИНИЦ \\ (на примере терминов сферы астрономии)
}

\begin{abstract}
Аннотация. В статье раскрываются особенности терминов как лексических единиц специальной сферы на примере англоязычных терминов сферы астрономии. Анализ проводился на материале выборки терминологических единиц общим объёмом около 2000 единии, отобранных из словарей астрономических терминов и других источников. Обосновываются два подхода к изучению природы термина: нормативный и дескриптивный. Подробно рассматриваются требования, предъявляемые к термину как специальной лексической единице, такие как системность, независимость от контекста, однозначность, точность, краткость и др. В ходе работы использовались такие методы исследования, как контекстуальный и этимологический виды анализа, компонентный анализ структуры терминологических единиц, метод реконструкции структурных и словообразовательных моделей исследуемых единии, количественной обработки данных. В результате работы автор приходит к выводу о том, что обязательными требованиями, которым должен соответствовать астрономический термин, являются соответствие нормам и правилам современного английского языка, систематичность, наличие дериниции, точность, краткость. К желательным характеристикам англоязычного астрономического термина относятся относительная независимость от контекста, однозначность, отсутствие синонимов, экспрессивную нейтральность и благозвучность. Если таким требованиям, как отсутствие экспрессии и благозвучность, соответствует большая часть терминов сферы астрономии, то требования однозначности и несинонимичности не удовлетворяются по крайней мере в объёме одной трети терминологической выборки.
\end{abstract}

Ключевые слова: термин, терминология, астрономия, требование, терминосистема, словарь, звезда, созвездие, небесное тело, синонимия.

Abstract. The article reveals some peculiarities of terms as specialized lexical units based on the example of the Englishlanguage astronomy terms. The carried out analysis is based on the material of the selection of terminological units of the total amount of 2000 units taken from dictionaries of astronomy terms and other sources. Two approaches to the study of the term's nature are substantiated: normative and descriptive. The author of the article examines the requirements to the term as a special lexical unit such as systemacy, independence from the context, monosemanticity, exactness, conciseness, etc. The following methods have been used during the research: the methods of contextual and etymological analysis, component analysis of the structure of terminological units, reconstruction of structural and word-formative models of the lexical units under study, and quantitative processing of data. As a result of the research the author comes to the conclusion that the obligatory requirements of the astronomy term include the conformity with the norms and rules of the modern English language, systemacy, presence of definition, exactness, and conciseness. Desirable characteristics of the English-language astronomy term are relative independence from the context, monosemanticity, absence of synonyms, expressive neutrality and harmony. If the major part of astronomy terms meets the requirements of absence of expressiveness and harmony, one third of the amount of terminological selection does not satisfy the requirements of monosemanticity and non-synonymy. Key words: constellation, star, dictionary, terminological system, requirement, astronomy, terminology, term, celestial body, synonymy.

«Астрономия полезна потому, что она возвышает нас над нами самими; она полезна потому, что она величественна; она полезна потому, что она прекрасна. Именно она являет нам, как ничтожен человек телом и как он велик духом, ибо ум его в состоянии объять сияющие бездны, где его тело является лишь тёмной точкой...»

(Анри Пуанкаре)
Астрономия, как следует из этимологии слова

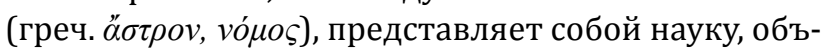
ектом изучения которой являются небесные тела. В рамках астрономии рассматриваются такие вопросы, как движение небесных тел, реальное и кажущееся, и законы этого движения; формы, размеры, 
массы, особенности поверхности природных космических объектов; их природа, устройство и физические свойства; эффекты, которые возникают при их взаимодействии путем притяжения и излучения; вероятные прошлое и будущее небесных тел [1].

Мы живём в эпоху космических открытий, когда человек смог оказаться на орбите планеты, преодолев гравитацию, которая несколько тысячелетий удерживала его на Земле. Сегодня благодаря различным космическим аппаратам человек приоткрыл плотный занавес атмосферы, скрывавший от него всевозможные сигналы и «послания» из открытого космоса. В результате использования различных приборов и инструментов мы можем «видеть» Вселенную в ультрафиолетовом, рентгеновском, инфракрасном и радиоизлучении. Кроме того, человек проник в суть вопроса об источниках энергии во Вселенной. Ядерные реакции, которые позволяют звёздам светить миллиарды лет, сейчас в достаточной мере изучены, а применение знаний о природе ядерных реакций способствует развитию промышленности. Несмотря на то, что звёзды напрямую не раскрывают секреты своего свечения, благодаря данным небесным телам люди поняли, что подобные секреты существуют. На протяжении истории звёзды служили своего рода маяками, которые давали человечеству надежду и уверенность в том, что тщательное исследование природных кладовых знаний может привести к открытию новых источников энергии и раскрытию других секретов, скрытых в течение миллионов лет [2].

Астрономия - одна из самых древних наук о Bceленной, а её основным методом, дающим результаты для последующего осмысления, является метод наблюдения. Объекты исследования астрономии весьма разнообразны и включают Землю (the Earth) и Луну (the Moon), другие планеты и их спутники, кометы, метеоры и метеориты, Солнце (the Sun) и звёзды, созвездия и астеризмы, туманности, галактики и внегалактические объекты, чёрные дыры, различные виды материи, формирующей космическое пространство [см.: 3; 4] и т.д. Вследствие бурного развития, обусловленного научно-техническим прогрессом, современная астрономия включает в себя различные новые отрасли, в рамках которых применяются инновационные методы исследований: к подобным отраслям можно отнести астрометрию, астрофизику, теоретическую астрономию, небесную механику, радиоастрономию, инфракрасную, ультрафиолетовую, рентгеновскую астрономию, гамма-астрономию, космохимию, ракетную и спутниковую астрономию, звездную астрономию, космогонию, космологию и др. Благодаря астрономии мы можем ориентироваться во времени и пространстве, как в течение относительно корот- ких промежутков времени (день, ночь), так и на протяжении более длинных в результате создания календарей (месяц, сезон, год). Ориентация в пространстве становится возможной с учётом положения звёзд (в частности, Полярной звезды, всегда указывающей на север - the North Star, the Pole Star) и созвездий. Развитие астрономии как науки, вызванное близостью человека к природе и стихийным зарождением социальных потребностей [5], способствовало, в частности, становлению соответствующей терминологии. В рамках данной статьи предпринимается попытка проанализировать основные особенности и характеристики терминов как единиц специальной лексики на примере англоязычных терминов сферы астрономии с целью выявления обязательных и желательных характеристик данных терминологических единиц. Материалом для анализа послужила выборка терминологических единиц общим объёмом 2000 единиц, отобранных, в частности, из «Англо-русско-английского астрономического словаря» [6], «Русско-английского астрономического словаря» [7] и других источников. В рамках методологии исследования следует отметить как общенаучные принципы (системность, междисциплинарность, антропоцентризм и т.д.), так и частнонаучные методы поиска, сбора и обработки данных. Последние включают метод сплошной выборки терминов, методы контекстуального, компонентного, этимологического, дефиниционного и контент-анализа и т.д.

Как известно, лексика любого языка может быть разделена на специальную и общеупотребительную, условно говоря, на термины и нетермины. Общеупотребительная лексика - нетермины - это слова, использование которых является относительно свободным, не ограниченным конкретной сферой или определённым предметом коммуникации. В рамках специальной лексики можно, в частности, выделить термины и профессионализмы как лексику, употребляемую отраслевыми специалистами $[8$, с. 158]. Естественно, что прямое противопоставление «термин» - «слово» неправомерно, так как термин базируется на лексической единице определённого естественного языка, она является субстратом для его формирования. Термины - это логически производные единицы [9, с. 91], образованные в результате изменения (например, специализации или расширения) значения лексической единицы. «Термин берёт (и сохраняет!) от лексической единицы определённого естественного языка лишь то, что может быть названо его языковым субстратом, а главным в термине является его терминологическая сущность, то есть способность оптимально выполнять функцию обозначения специального общего понятия в системе понятий из- 
вестной специальной области знаний или деятельности» $[10$, с. 21$]$.

Существует, по крайней мере, два подхода к изучению природы термина: 1) нормативный (с формулировкой требований к термину) и 2) дескриптивный (предполагающий, что любое слово может выступать в роли термина, последний может быть многозначным и иметь синонимы) [9, с. 87]. В целом, по мнению В.М. Лейчика, термин не сводится полностью к лексической единице, так как имеет особые специфические признаки. Термин - это сложное многослойное образование, «в котором естественноязыковой субстрат и логический суперстрат образуют соответственно нижний и верхний слои, а сердцевину его составляет терминологическая сущность, включающая специфическую концептуальную, функциональную и формальную структуру» $[10$, с. 21]. Термин, который может представлять собой однословную единицу (damping затухание, aberration - аберрация, zenith - зенит) или словосочетание (quadrupole multiplet - квадрупольный мультиплёт; star atlas - звёздный атлас, white dwarf star - белый карлик), выполняет номинативную функцию, т.е. называет специальное (строго определённое интенсионально и экстенсионально) понятие. Термины создаются в процессе профессиональной деятельности и служат целям научно-профессиональной коммуникации. Данные лексические единицы могут иметь особое, скрытое от простого человека-неспециалиста специальное значение. Слово «специальный» в данном случае предполагает соотнесённость с профессиональной деятельностью (в этой связи становится релевантной категория профессионального деятеля как субъекта профессиональной, терминологически нагруженной, коммуникации - см. подробнее $[11 ; 12$; 13]). Таким образом, термин - это «слово или словосочетание специального (научного, технического) языка, создаваемое (принимаемое, заимствуемое) для точного выражения специальных понятий и обозначения специальных предметов» [14, с. 474]. В итоге, в рамках приведённого определения выражается формальный признак термина и его понятийная сущность. Кроме того, под термином зачастую понимается слово, требующее определённого разъяснения, дефиниции для обывателей в связи с его специальным характером и сложностью осмысления его семантики неспециалистами.

Согласно Д.С. Лотте, к термину как специальной единице предъявляются требования, такие как системность, независимость от контекста, однозначность, точность, краткость. При этом при создании термина зачастую может реализоваться либо требование точности, либо краткости [15, с. 72-76]. 0 требованиях к однозначности/отсутствии полисе- мии [см., напр.: 16, с. 117] и синонимии [17] терминов говорят и другие учёные [см. также: 18].

Наиболее полный список требований к термину, на наш взгляд, приведён в работе Т.Р. Кияка «Лингвистические аспекты терминоведения» $[19$, с. 8-9]; в этот список автор включает следующие параметры:

1) соответствие нормам и правилам соответствующего языка;

2) систематичность;

3) наличие чёткого определения, дефиниции;

4) относительная независимость от контекста;

5) точность;

6) краткость (как уже упоминалось выше, данное требование в некоторых случаях вступает в противоречие с требованием точности, т.е. полноты термина);

7) стремление к однозначности в рамках одной терминосферы;

8) отсутствие синонимичности, мешающей взаимопониманию в рамках научно-профессиональной коммуникации;

9) экспрессивная нейтральность;

10) благозвучие (благозвучность).

Соответствие термина всем указанным требованиям на практике, в реальной научно-профессиональной коммуникации, практически невозможно [см. в этой связи: $20 ; 21 ; 22 ; 23 ; 24 ; 25 ; 26]$. Мы рассмотрим далее каждую из приведённых характеристик применительно к терминологии сферы астрономии с целью выявления степени обязательности/желательности заявленных параметров терминологичности.

Соответствие нормам и правилам языка проявляется, в частности, в том, что англоязычные термины сферы астрономии сформированы по тем же деривационным моделям, что и общеупотребительная лексика, при этом, однако, каждая терминосистема отдаёт предпочтение каким-то определённым конкретным моделям [см., в частности: 27; $28 ; 29 ; 30 ; 31 ; 32]$. В случае с астрономической терминологией наблюдаем частотное использование следующих деривационных моделей: префиксации (anti- (antiglow - противосияние); micro- (micrometeorite - микрометеорит); multi(multipole - мультиполь, мультиполюсный); circum- (circumstellar - околозвёздный); counter(counterglow - противосияние)); суффиксации (-ing (cratering - образование кратера); -er/-or (polarizer поляризатор; corrector - корректор, коррекционная линза); -(a)tion/-sion/-ion (approximation - аппроксимация, приближение; gravitation - гравитация; collision - столкновение)); префиксально-суффиксального способа (circumnavigation - облет (Луны)); осново- и словосложения (blackbody (laws) - законы 
излучения чёрного тела); сокращения и аббревиации ( $D Q E$ (detective quantum efficiency) - квантовая эффективность обнаружения); синтаксического способа, в результате которого образуются термины-словосочетания (star cluster - звёздное скопление mechanism of radio emission - механизм радиоизлучения) [6]. Таким образом, первая из перечисленных характеристик представляется вполне релевантной для изучения терминологии астрономии.

Систематичность (системность) терминов сферы астрономии базируется на классификации соответствующих астрономических понятий, исходя из которой выделяются необходимые и достаточные признаки, включаемые в семантическую структуру термина, после чего подбираются слова и их части (основообразующие и классифицирующие терминоэлементы) для образования терминологической единицы [33; 34; 35; 36; 37; 38]. Другим параметром, непосредственно связанным с системностью термина, является его мотивированность, т.е. семантическая прозрачность, позволяющая составить представление о называемом термином специальном понятии. Систематичность подразумевает возможность отражения в структуре термина его определённого места в соответствующей терминосистеме, связи называемого понятия с другими, его отнесённости к определённой логической категории понятий [15]. Например, одним из факторов и показателей мотивированности выступают гипо-гиперонимические (родовидовые) отношения между терминологическими единицами: если рассматривать термин star (звезда) как семантический гипероним, тогда термины yellow dwarf star (жёлтый карлик), orange dwarf star (оранжевый карлик), red dwarf star (красный карлик), brown $d w a r f$ (коричневый карлик), blue giant star (голубой гигант), red giant star (красный гигант), red supergiant star (красный сверхгигант), white dwarf (белый карлик), black dwarf (чёрный карлик), neutron star (нейтронная звезда) [39] будут выступать гипонимами, семантически и структурно связанными отношениями мотивации с гиперонимом.

В рамках терминов, обозначающих приборы и инструменты в сфере астрономии, также присутствуют гипо-гиперонимические отношения: гипероним astronomic tool (астрономический инструмент) - гипоним telescope (телескоп); при этом последняя лексическая единица является уже гиперонимом, т.е. вербализатором родового понятия, для следующих единиц: optical telescope - оптический телескоп, solar telescope - солнечный телескоп; space telescope - космический телескоп, zenith telescope - зенитный телескоп, infrared telescope инфракрасный телескоп, Schmidt telescope - теле- скоп Шмидта и т.д. Гипонимами термина astronomic tool являются и такие термины-историзмы, как astrolabe (астролябия), sextant (секстант), armillary sphere (spherical astrolabe, armilla, armil) (армиллярная сфера), quadrant (квадрант), gnomon (гномон), octant (октант), skafis (скафис), cosmolabe (космолябия, универсальный инструмент), astereometer (астереометр), auxотеter (ауксометр), triquetrum (трикветрум) и т.д.

Термин telescope (телескоп) стали использовать первоначально в латинской форме с 1619 г. Данная единица происходит от итал. telescopio (Галилео Галилей, 1611) и новолат. telescopium (И. Кеплер, 1613); оба слова от греч. teleskopos «дальновидный», от tele- «далёкий, дальний» + -skopos «наблюдатель» [40].

Системность терминов также проявляется и в однотипности терминоэлементов и их частей у однотипных терминов [37; 41; 42; 43]; например, в английском языке один и тот же суффикс -oid используется при наименовании некоторых космических объектов и их свойств (при этом, как правило, при номинации профилируется признак формы или размера): asteroid (астероид), planetoid (малая планета, астероид), meteoroid (метеороид), spheroid (сфероид), conoid (коноид, усечённый конус), ellipsoid (эллипсоид), paraboloid (параболоид), geoid (геоид), hyperboloid (гиперболоид) и т.д.

Практически любой термин в большинстве развитых языков, возможно, за исключением некоторых терминов-неологизмов, имеет более или менее чёткое научное определение или дефиницию. Например, можно встретить следующую дефиницию астрономического термина supernova (сверхновая звезда): A supernova is an explosion of a massive supergiant star. It may shine with the brightness of 10 billion suns. The total energy output may be 1044 joules, as much as the total output of the sun during its 10 billion year lifetime. The likely scenario is that fusion proceeds to build up a core of iron [44]. (Сверхновая звезда - это взрыв массивной звезды-сверхгиганта. Она может светить с яркостью в 10 миллиардов раз больше, чем Солнце. Общий выход энергии может составлять 1044 джоул, столько же, сколько Солнце испускает за 10 миллиардов лет. Вероятным сценарием является слияние ядер элементов с формированием железного ядра (Перевод наш - А.С.)).

Следует отметить, что термин может иметь несколько дефиниций, данных разными учёными, приведённых в разных словарях и другой научно-справочной литературе [см. подробнее: 45; 46]. Например, астрономический термин constellation (созвездие) имеет по крайней мере две дефиниции простую, походящую скорее на простое определение для неспециалистов, и официальную. Сам термин 
constellation употребляется с начала XIV в., в виде constellacioun («позиция планеты в Зодиаке»), а с конца XIV в. - в значении «одна из признанных групп звёзд из древности» (в составе Зодиака или нет), происходит от древнефр. constellacion «созвездие, комбинация (планет)», от древнелат. constellationem (им.п. constellatio) «констелляция, взаимное положение небесных тел», от constellatus, от лат. com- «с»+ причастие прошедшего времени от stellare «сверкать», от stella «звезда»). Первоначальное значение термина астрологическое, связанное с позицией планет («звёзд») относительно созвездий в определённый день, в частности, в день рождения какого-либо человека, что определяет его характер [40].

Приведём дефиниции термина constellation (coзвездие) и их перевод:

A simple definition of a constellation is a group of stars which form a pattern in the night sky [47]. / Простая дефиниция: созвездие - это группа звезд, которая формирует какой-либо узор на ночном небе.

The official definition is an area of the sky with defined boundaries, all stars and any other objects within that boundary are considered part of the constellation [47]. (Официальная дефиниция: (созвездие) это область неба с определёнными границами, в рамках которых все звёзды и любые другие объекты рассматриваются как его часть (Перевод наш - А.C.)).

Относительная независимость термина от контекста подразумевает тот факт, что, в частности, «термины могут жить вне контекста, если известно, членами какой терминологии они являются» [34, с. 58]. По мнению Р.Ф. Прониной, любой термин следует рассматривать как «слово, за которым закреплено определённое техническое значение, но которое может изменить своё содержание в зависимости от той отрасли, в которой оно употреблено» $[48$, с. 8]. Так, термин/терминоэлемент star имеет древнеанглийское происхождение: образован от слова steorra «звезда», от протогерманского *sterron, *sternon (древнесаксонского sterro, древнефризского stera и т.д.), изначально из протоиндоевропейского *ster- «звезда» (также от санскритского star-, хеттского shittar, греческого aster, astron, латинского stella, бретонского sterenn со значением «звезда»). Есть мнение, что данный корень обозначал «разбрызгивать, разбрасывать» [40]. В целом, слово star (звезда) - общеупотребительное, общеизвестное, однако в рамках контекста - научных текстов/научно-профессионального дискурса оно приобретает черты терминологичности и закрепляется дефиницией:

A star is a massive, luminous sphere of plasma held together by gravity. The nearest star to Earth is the Sun, which is the source of most of the energy on the planet [49]. (Звезда - это массивная, излучающая свет плазменная сфера, удерживаемая силами собственной гравитации. Ближайшая к Земле звезда - это Солнце, являющееся источником значительной части энергии на нашей планете (Перевод наш - А.C.)).

Само слово sun, выступающее в качестве терминоэлемента англоязычных многокомпонентных терминов сферы астрономии, - это современный вариант древнеанглийского общеупотребительного слова sunne «солнце», от протогерм. *sunnon (также от древнесканд., древнесакс., древневерхненем. sunna, средненем. sonne, нем. zon, герм. Sonne, готск. sunno «солнце»), от протоиндоевропейского корня *s(u)wen-, альтернативная форма корня *saewel«светить, солнце» [40]. Терминоэлемент sun употребляется, в частности, в таких англоязычных терминах сферы астрономии, как Sun's axis (ось вращения Солнца), sun spot (солнечное пятно), sunlit aurora (полярное сияние, освещённое Солнцем), Sun's mass (солнечная масса), Sun's system (солнечная система), Sun's surface (поверхность Солнца), sunspot spectrum (спектр солнечных пятен), Sun tower (башенный солнечный телескоп) [6] и др.

Интересным термином сферы астрономии в современном английском языке является термин moon, который с 1665 г. стал обозначать не только Луну, но и спутники других планет (следствие семантического расширения). Слово тоon происходит от древнеангл. тола, от протогерм. *menоn- (также от древнесакс. и древневерхненем. mano, древнефриз. топа, древнесканд. mani, датск. maane, нем. maan, герм. Mond, гот. mena «луна»), от протоиндоевроп. *me(n)ses- «луна, месяц» (также от санскр. masah «луна, месяц»; греч. mene «луна», men «месяц»; лат. mensis «месяц»; древнеирланд. mi, валл. mis, брет. miz «месяц»), вероятно от корня *me«измерять», в частности, в отношении фаз луны как способа измерения времени [40].

Несмотря на то, что «для термина, с одной стороны, характерна соотнесённость с точно определённым понятием и стремлением к однозначности, вследствие чего ряд терминов приобретает некоторую независимость от контекста, это ещё не означает, что термины совершенно не зависят от контекста, но в нём выявляется их значение» [50, c. 24]. Рассмотрим, например, такой многозначный термин, как array, употребляющийся в различных сферах человеческой деятельности и соответствующих контекстах: 1) (battle array) строй, боевой порядок (военное дело); 2) список присяжных заседателей (юриспруденция); 3) сложная (антенная) система (астрономия) [51] и т.д. Понять, как именно необходимо перевести данный термин можно только исходя из тематической сферы текста, в котором он употреблён.

Точность терминологической единицы - это 
наличие логической определённости, адекватности термина как инструмента научного познания тем задачам, для решения которых он создан [см.: 52; 53]: наименования специального понятия, хранения и передачи специального знания. Так, например, термин/терминоэлемент Earth стал обозначать планету Земля со всеми свойственными ей характеристиками только с XIV в., хотя изначально происходил от древнеангл. еоrpe «земля, почва, грязь, сухая земля, местность, территория, округ», т.е. был в общем употреблении и обозначал обыденные объекты. В то же время он также использовался для обозначения «материального мира, места жительства человека» в отличие от небес и подземного мира, происходит от протогерм. *ertho (также от древнефриз. erthe «земля», древнесакс. ertha, древнесканд. jörð, средненем. eerde, нем. aarde, древневерхненем. erda, герм. Erde, готск. airpa), происходящей от расширенной формы протоиндоевропейского корня *er- «земля, почва» (также от среднеирланд. - ert «земля») [40].

Точность термина снимает проблему отграничения научных понятий и одной области (подобласти) научного знания от другой. Кроме того, от степени точности термина в прямой зависимости находится чёткость границ областей научного знания [21, с. 17].

Краткость терминологической единицы (как уже упоминалось выше, данное требование в некоторых случаях вступает в противоречие с требованием точности, т.е. полноты термина) подразумевает следование принципу языковой экономии. Прежде всего, это использование в сфере астрономии терминов с относительно небольшим количеством (до 5-6 компонентов) терминоэлементов, а также блендов и сложных слов (композитов) (astrobotany астроботаника; astrophotometer - астрофотометр), эллиптизированных терминов (Perseids (Perseid meteor shower) - Персеиды, метеорный поток, Pleiads (Pleiades star cluster) - Плеяды, рассеянное звёздное скопление в созвездии Тельца), многочисленных аббревиатур (например, названий созвездий: And (Andromeda) - Андромеда, Cnc (Cancer) - Рак, Нуа (Hydra) - Гидра, PsA (Piscis Austrinus) - созвездие Южная Рыба, CrB (Corona Borealis) - Северная Корона, CrA (Corona Australis) - Южная Корона), Tri (Triangulum) Треугольник, Lib (Libra) - Весы, Cru (Crux) - Южный Крест) и т.д. [6; 54].

Такое требование к термину, как однозначность, оспаривается многими лингвистами: сегодня доминирует мнение о том, что терминологическая единица лишь стремится к однозначности, и данный процесс происходит в рамках одной терминологической сферы [19, с. 9; 55-58 и др.]. Полисемия терминов - достаточно широко распростра- нённое явление, в том числе в сфере астрономии. Приведём некоторые примеры полисемичных терминов. Например, даже такой детерминологизированный термин/терминоэлемент, как planet (планета) является многозначным (происходит от позднего древнеангл. planete, от древнефр. planete (в современном французском языке - planète), от позднелат. planeta, от греч. planetes, от (asteres) planetai «странствующие (звёзды)», от planasthai «странствовать, блуждать» неизвестного происхождения, возможно, от протоиндоевропейского корня *pele- со значением «плоский; простираться, распространяться» [40]). Термин planet употребляется 1) для наименования планеты, небесного тела, вращающегося по эллиптической орбите вокруг звезды; 2) для обозначения планеты Земля, земного шара (the planet = the Earth); 3) для обозначения светила, например, Солнца или Луны [59].

Кроме приведённого выше требования об однозначности, учёные высказывают сомнения по поводу требования к экспрессивной нейтральности и отсутствию у термина синонимов, так как на практике, в реальной научно-профессиональной коммуникации у терминов бывают полные и частичные синонимы, некоторые термины обладают экспрессией.

Синонимичность терминов как явление может серьёзно помешать взаимопониманию в рамках научно-профессиональной коммуникации, особенно в том, что касается взаимоотношений между учёными разных стран. По мнению К.Я. Авербуха, в случае с терминами речь идёт скорее о полной идентичности, а не о схожести их значений, однако синонимия терминов этим не исчерпывается. По его мнению, она порождается такими основными факторами, как наличие наименований одного и того же объекта, процесса или явления, данных в рамках разных областей человеческой деятельности (терминоэлементы anagalactic (extragalactic) внегалактический и external - внешний, внегалактический; external policy - внешняя политика (политология)), метонимическим употреблением одного из терминов синонимической пары (fiber - волокно и filament - волокно, волосок), а также активным заимствованием (albedo - альбедо и reflecting) reflection power - отражательная способность, коэффициент отражения) [см.: 60; 61; 62]. В.М. Лейчик также подчёркивает тот факт, что вариантность и синонимия как её частный случай присущи терминам, их нельзя избежать [10, с. 29].

В сфере астрономии присутствуют синонимичные (структурные и семантические) варианты наименований звёзд, созвездий и астеризмов, других космических объектов: звезда Вега - Vega, Wega, Alpha Lyrae, Alpha Lyr, $\alpha$ Lyrae, $\alpha$ Lyr; звезда Сириус Sirius, the Dog Star, Alpha Canis Majoris, $\alpha$ CMa; Поляр- 
ная звезда - North Star, Polaris, Pole Star, $\alpha$ UMi; Coзвездие Малая Медведица - Cynosure, the Little Bear, Ursa Minor, UMi, Little Dipper, Dog's tail; созвездие Плеяды - the Pleiades, Seven Sisters, Messier 45, M45; метеор - meteor, shooting star, falling star [6; 63 и др.] и т.д.

Экспрессивная нейтральность у термина проявляется в отсутствии коннотации в его семантике [64; 65], однако на практике существуют термины, в которых в той или иной степени выражено положительное или отрицательное отношение к содержанию специального понятия, обозначаемого данным термином [66, с. 24-25], в которых заключён тот или иной образ или которые образованы от эмоционально окрашенных слов, например: wing крыло (спектральной линии), air-leg - пневмоподдержка, пневматический толкатель, arm - консоль, рукав/ветвь (спиральной структуры галактики), east(ern) limb - восточный край диска (Солнца), star ageing - старение звезды и т.д. Естественно, что в основном англоязычные термины сферы астрономии являются экспрессивно нейтральными.

Требование к благозвучности предполагает, с одной стороны, удобство произношения и собственно благозвучие, с другой стороны. Естественно, что термин не должен вызывать различных негативных ассоциаций вне узкоспециального употребления. Примерами англоязычных терминов сферы астрономии с низкой степенью благозвучности, на наш взгляд, являются следующие (главным образом, заимствованные транслитерированные и транскрибированные) единицы: antalgol - анталголь, Schwarzschield (black hole) - шварцшильдовская чёрная дыра, Herbig-Haro (object) - ХербигаАро объект, Stromgren sphere - сфера Стремгрена, fluxule - флюксула (flux - истечение; слюнотечение, слёзотечение и т.д.) и т.д. В большинстве своём терминологические единицы сферы астрономии являются благозвучными.

Таким образом, мы приходим к выводу о том, что термин - это специальная лексическая единица, обладающая некоторыми свойствами и признаками и удовлетворяющая определённым требованиям. На примере англоязычных терминов сферы астрономии было выявлено, что обязательными требованиями, которым должен соответствовать астрономический термин, являются соответствие нормам и правилам современного английского языка, систематичность, наличие дефиниции (за небольшим исключением), точность, краткость. К желательным характеристикам англоязычного астрономического термина, в целом, можно отнести относительную независимость от контекста, однозначность, отсутствие синонимов, экспрессивную нейтральность и благозвучность. Если последним двум требованиям (отсутствие экспрессии и благозвучность) соответствует большая часть терминов сферы астрономии, то требования однозначности и несинонимичности не удовлетворяются, по нашим подсчётам, по крайней мере в объёме одной трети терминологической выборки в 2000 единиц.

\section{Список литературы:}

1. Russell H.N., Dugan R.S., Stewart J.Q. Astronomy: A Revision of Young's Manual of Astronomy. Vol. 1. Boston: Ginn, 1926.510 p.

2. Rudaux L., Vaucouleurs G.De, Whipple F.L. Larousse Encyclopedia of Astronomy. 2nd ed. New York: Prometheus Press, $1962.542 \mathrm{p}$.

3. Sparke L.S., Gallagher III J.S. Galaxies in the Universe: An Introduction. Cambridge University Press, 2007.442 p.

4. Motz L., Weaver J.H. The Story of Astronomy. Cambridge, MA: Perseus Publishing, 1995. 398 p.

5. Саидова М.Г. История формирования астрономической терминологии в сопоставляемых языках // Вестник Таджикского государственного университета права, бизнеса и политики. Серия гуманитарных наук. 2012 . Вып. № 2. C. 206-212.

6. Англо-русско-английский астрономический словарь. [Электронный ресурс] URL: http://astronet.ru/db/dict/ (дата обращения: 01.09.2016).

7. Муртазов А.К. Русско-английский астрономический словарь. Рязань, 2010. 180 с.

8. Татаринов В.А. Теория терминоведения: в 3 т. Т. 1. Теория термина: история и современное состояние. М.: Московский лицей, 1996. 311 с.

9. Лейчик В.М. О языковом субстрате термина // Вопросы языкознания. 1986. № 5. С. 87-97.

10. Лейчик В.М. Проблемы отечественного терминоведения в конце XX века // Вопросы филологии. 2000. № 2. С. 20-29.

11. Голованова Е.И. Категория профессионального деятеля: формирование, развитие, статус в языке. М.: ЭЛПИС, 2008. $304 \mathrm{c}$.

12. Голованова Е.И. Профессиональный дискурс, субдискурс, жанр профессиональной коммуникации: соотношение понятий // Вестник Челябинского государственного университета. 2013. № 1 (292). С. 32-35.

13. Новодранова В.Ф. Учебные словари профессиональной коммуникации // Научные и методические проблемы медицинской терминологии: Материалы Международной учебно-научно-методической конференции заведующих кафедрами (курсами) латинского языка и основ терминологии высших медицинских и фармацевтических учебных заведений / Под ред. В.И. Мидленко. Ульяновск, 2009. С. 15-16.

14. Ахманова О.С. Словарь лингвистических терминов. М.: Сов. энциклопедия, 1966. 571 с.

15. Лотте Д.С. Основы построения научно-технической терминологии. Вопросы теории и методики. М.: Изд-во АН CCCP, $1961.160 \mathrm{c}$. 


\section{Лингвистика}

16. Галкина-Федорук Е.М. Слово и понятие. М.: Учпедгиз, 1956. 154 с.

17. Казанчян Л.О. Некоторые вопросы терминологии // Вестн. Ереван. ун-та. 1971. С. 232-234.

18. Аликаев Р.С. К проблеме точности термина // Вестник Кабардино-Балкарского государственного университета. 1994. № 1. С. 3-6.

19. Кияк Т.Р. Лингвистические аспекты терминоведения. Киев: УМКВО, 1989. 103 с.

20. Лату М.Н. Основные характеристики термина в современном английском языке: эталон и динамика (на материале современного английского языка военно-исторической терминологии) // Вестник Пятигорского государственного лингвистического университета. 2009. № 2. С. 93-96.

21. Лату М.Н., Раздуев А.В. Терминоведение: частные вопросы развивающихся терминологий: учебное пособие к лекционному курсу «Общие и прикладные аспекты терминоведения». Пятигорск, 2011. 132 с.

22. Горбунова Н.Н. Основные характеристики англоязычной терминосистемы сферы менеджмента и её тематическая стратификация // Вестник Пятигорского государственного лингвистического университета. 2014 . № 2. C. 76-83.

23. Лату М.Н., Алимурадов О.А. К вопросу об универсальных и индивидуальных характеристиках терминосистем (на материале англоязычной военно-исторической терминологии) // Язык. Текст. Дискурс. 2008. № 6. С. 250-255.

24. Раздуев А.В. Дискурс сферы нанотехнологий как вид научного дискурса (на материале современного английского языка) // Вестник Челябинского государственного университета. 2013. № 37 (328). С. 52-55.

25. Ивина Л.В. Лингво-когнитивные основы анализа отраслевых терминосистем (на примере англоязычной терминологии венчурного финансирования): учебно-методическое пособие. М.: Академический проект, 2003. 304 с.

26. Аликаев Р.С., Чихрадзе А.М. О сущностных характеристиках дефиниции, понятия и термина // Вестник Кабардино-Балкарского государственного университета. 2000. № 4. С. 61-63.

27. Хакиева 3.У. Семантические и структурные особенности англоязычной терминологии: современное состояние и динамика развития // Язык и ментальность Сер. «Славянский мир». СПб., 2010. С. 344-351.

28. Раздуев А.В. Сравнительно-сопоставительный анализ семантики, структуры и динамики русского и английского подъязыков сферы нанотехнологий // Вестник Челябинского государственного университета. 2011. № 24. С. 167 170.

29. Кожеватова Д.С., Алимурадов О.А., Раздуев А.В. Некоторые структурно-словообразовательные модели англоязычной юридической терминологии // Актуальные проблемы филологии и педагогической лингвистики. 2015 . № 4 (20). С. 44-55.

30. Акаева Х.А., Бугаенко Н.П., Докуто Б.Б., Жуликов Е.В. Вопросу о возможных параметрах структурного и семантического описания терминологических систем: внутриязыковой и межъязыковой аспекты // Вестник Пятигорского государственного лингвистического университета. 2013. № 2. С. 68-76.

31. Алимурадов О.А., Горбунова Н.Н. Основные синтаксические словообразовательные модели, реализуемые в англоязычной терминологии менеджмента // Известия высших учебных заведений. Серия: Гуманитарные науки. 2014. T. 5. № 2. С. 95-101.

32. Горбунова Н.Н., Алимурадов О.А. Тематические, структурно-словообразовательные и семантические особенности англоязычной терминологии сферы менеджмента // Бородин П.А., Горбунова Н.Н., Алимурадов О.А. и др. Современное состояние и перспективные векторы развития филологии, лингвистики, языкознания и коммуникативистики: в 3 т. / Под науч. ред. О.П. Чигишевой. Ростов-на-Дону, 2014. С. 30-64.

33. Виноградов В.А. Всегда ли система системна? // Система и уровни языка. М.: Наука, 1969. С. 249-259.

34. Реформатский А.А. Термин как член лексической системы языка // Проблемы структурной лингвистики. М.: Наука, 1968. 343 с.

35. Климовицкий Я.А. Термин и обусловленность определения понятия в системе // Проблематика определений терминов в словарях разных типов. Л.: Наука, 1976. С. 107-114.

36. Лату М.Н. Мотивация термина и дефиниция: система корреляций // Scientific Review. Proceedings of the international scientific conference. 2015. С. 280-287.

37. Алимурадов О.А., Лату М.Н., Раздуев А.В. Особенности структуры и функционирования отраслевых терминосистем: на примере терминосистемы нанотехнологий. 2-е изд., испр. и доп. Пятигорск, 2012. 128 с.

38. Шелов С.Д. Термин. Терминологичность. Терминологические определения. Серия: Филологические исследования. СПб.: Филол. факультет СПбГУ, 2003. 280 с.

39. Different types of stars in the Universe. [Электронный ресурc] URL: https://owlcation.com/stem/Different-Types-ofStars-in-the-Universe (дата обращения: 10.09.2016).

40. Online Etymology Dictionary. [Электронный ресурc] URL: http://www.etymonline.com/ (дата обращения: 01.09.2016).

41. Некрасова Т.В. Системность организации терминологических единиц в сфере профессиональной коммуникации // Вестник Башкирского университета. 2007. Вып. 4. Т. 12. С. 115-118.

42. Канделаки Т.Л. Значения терминов и системы значений научно-технических терминологий // Проблемы языка науки и техники. М., 1977. С. 12-92.

43. Толикина Е.Н. Некоторые лингвистические проблемы изучения термина. М.: Наука, 1984. 254 c.

44. Supernovae. [Электронный ресурс] URL: http://hyperphysics.phy-astr.gsu.edu/hbase/astro/snovcn.html (дата обращения: 10.09.2016).

45. Макарихина О.А. Анализ и моделирование понятийной структуры терминов социально-гуманитарных наук (на примере термина «этнос»): Автореф. дисс. ... канд. филос. наук. Нижний Новгород, 2007. 24 с.

46. Лату М.Н. Номинация в развивающихся терминосистемах. Пятигорск: СНЕГ, 2015. 192 с.

47. Star constellations. [Электронный ресурc] URL: http://www.solarsystemquick.com/universe/star-constellations.htm (дата обращения: 10.09.2016).

48. Пронина Р.Ф. Перевод английской научно-технической литературы: учеб. пособие для втузов. 3-е изд., испр. и доп. М.: Высш. шк., 1986. 175 с. 


\section{Филология: научные исследования 4(24) • 2016}

49. The stars. The Center for Planetary Science. [Электронный ресурc] URL: http://planetary-science.org/astronomy/thestars / (дата обращения: 10.09.2016).

50. Ц Циткина Ф.А. Терминология и перевод: (К основам сопоставительного терминоведения). Львов: Вища школа, Издво при Львов. гос. ун-те, 1988. 162 с.

51. Array. Webster's Revised Unabridged Dictionary. [Электронный pecypc] URL: http://biblehub.com/topical/a/array.htm (дата обращения: 10.09.2016).

52. Новоселов М.М. Логика абстракций (методологический анализ). М., 2000. Ч. І. 191 с.

53. Бугорская Н.В. Ещё раз о точности термина // Сибирский филологический журнал. 2008. № 3. С. $211-219$.

54. Кононович Э.В., Мороз В.И. Общий курс астрономии: учебное пособие / Под ред. В.В. Иванова. М.: Едиториал УРСС, 2004. $544 \mathrm{c.}$

55. Лату М.Н. Англоязычная военная терминология в её историческом развитии: структурно-семантический и когнитивно-фреймовый аспекты: Дисс. ... канд. филол. наук. Ростов-на-Дону, 2009. 222 с.

56. Лату М.Н., Раздуев А.В. Причины и модели возникновения синонимии у терминов в сфере фиксации // Вестник Пятигорского государственного лингвистического университета. 2011. № 2. С. 142-145.

57. Раздуев А.В. Современный английский подъязык нанотехнологий: структурно-семантическая, когнитивно-фреймовая и лексикографическая модели: Дисс. ... канд. филол. наук. Пятигорск, 2013. 242 с.

58. Алимурадов О.А., Лату М.Н. Особенности моделирования семантики терминоединиц. терминологические оппозиции (на материале англоязычной военной терминологии) // Вестник Иркутского государственного лингвистического университета. 2010. № 3. С. 6-15.

59. Planet. Dictionary.com. [Электронный ресурc] URL: http://www.dictionary.com/browse/planet (дата обращения: 01.09.2016).

60. Авербух К.Я. Терминологическая вариантность; теоретические и прикладные аспекты // Вопросы языкознания. 1986. № 6. С. 38-49.

61. Temmerman R. Towards New Ways of Terminology Description. The Sociocognitive approach. Amsterdam, 2000.258 p.

62. Picht H., Draskau J. Terminology: An Introduction. Copenhagen, 1985. 255 p.

63. Ridpath I. A Dictionary of Astronomy. Oxford: Oxford University Press, 1997. 544 p.

64. Капанадзе Л.А. О понятиях «термин» и «терминология» // Развитие лексики современного русского языка. М., 1965. С. 75-86.

65. Реформатский А.А. Мысли о терминологии // Современные проблемы русской терминологии. М., 1986. С. 163-198.

66. Прохорова В.Н. Семантика термина // Вестник Моск. ун-та. Сер. 9. Филология. 1981. № 3. С. 24-25.

\section{References (transliterated):}

1. Russell H.N., Dugan R.S., Stewart J.Q. Astronomy: A Revision of Young's Manual of Astronomy. Vol. 1. Boston: Ginn, 1926. 510 p.

2. Rudaux L., Vaucouleurs G.De, Whipple F.L. Larousse Encyclopedia of Astronomy. 2nd ed. New York: Prometheus Press, $1962.542 \mathrm{p}$.

3. Sparke L.S., Gallagher III J.S. Galaxies in the Universe: An Introduction. Cambridge University Press, 2007.442 p.

4. Motz L., Weaver J.H. The Story of Astronomy. Cambridge, MA: Perseus Publishing, 1995. 398 p.

5. Saidova M.G. Istoriya formirovaniya astronomicheskoi terminologii v sopostavlyaemykh yazykakh // Vestnik Tadzhikskogo gosudarstvennogo universiteta prava, biznesa i politiki. Seriya gumanitarnykh nauk. 2012. Vyp. № 2. S. 206-212.

6. Anglo-russko-angliiskii astronomicheskii slovar'. [Elektronnyi resurs] URL: http://astronet.ru/db/dict/ (data obrashcheniya: 01.09.2016).

7. Murtazov A.K. Russko-angliiskii astronomicheskii slovar'. Ryazan', 2010. $180 \mathrm{s.}$

8. Tatarinov V.A. Teoriya terminovedeniya: v 3 t. T. 1. Teoriya termina: istoriya i sovremennoe sostoyanie. M.: Moskovskii litsei, 1996. $311 \mathrm{~s}$.

9. Leichik V.M. O yazykovom substrate termina // Voprosy yazykoznaniya. 1986. № 5. S. 87-97.

10. Leichik V.M. Problemy otechestvennogo terminovedeniya v kontse XX veka // Voprosy filologii. 2000. № 2. S. 20-29.

11. Golovanova E.I. Kategoriya professional'nogo deyatelya: formirovanie, razvitie, status v yazyke. M.: ELPIS, 2008.304 s.

12. Golovanova E.I. Professional'nyi diskurs, subdiskurs, zhanr professional'noi kommunikatsii: sootnoshenie ponyatii // Vestnik Chelyabinskogo gosudarstvennogo universiteta. 2013. № 1 (292). S. 32-35.

13. Novodranova V.F. Uchebnye slovari professional'noi kommunikatsii // Nauchnye i metodicheskie problemy meditsinskoi terminologii: Materialy Mezhdunarodnoi uchebno-nauchno-metodicheskoi konferentsii zaveduyushchikh kafedrami (kursami) latinskogo yazyka i osnov terminologii vysshikh meditsinskikh i farmatsevticheskikh uchebnykh zavedenii / Pod red. V.I. Midlenko. Ul'yanovsk, 2009. S. 15-16.

14. Akhmanova O.S. Slovar' lingvisticheskikh terminov. M.: Sov. entsiklopediya, 1966. $571 \mathrm{~s}$.

15. Lotte D.S. Osnovy postroeniya nauchno-tekhnicheskoi terminologii. Voprosy teorii i metodiki. M.: Izd-vo AN SSSR, 1961. $160 \mathrm{~s}$.

16. Galkina-Fedoruk E.M. Slovo i ponyatie. M.: Uchpedgiz, 1956. 154 s.

17. Kazanchyan L.O. Nekotorye voprosy terminologii // Vesti. Erevan. un-ta. 1971. S. 232-234.

18. Alikaev R.S. K probleme tochnosti termina // Vestnik Kabardino-Balkarskogo gosudarstvennogo universiteta. 1994 . № 1. S. 3-6.

19. Kiyak T.R. Lingvisticheskie aspekty terminovedeniya. Kiev: UMKVO, 1989.103 s.

20. Latu M.N. Osnovnye kharakteristiki termina v sovremennom angliiskom yazyke: etalon i dinamika (na materiale sovremennogo angliiskogo yazyka voenno-istoricheskoi terminologii) // Vestnik Pyatigorskogo gosudarstvennogo lingvisticheskogo universiteta. 2009. № 2. S. 93-96.

21. Latu M.N., Razduev A.V. Terminovedenie: chastnye voprosy razvivayushchikhsya terminologii: uchebnoe posobie $\mathrm{k}$ lektsionnomu kursu «Obshchie i prikladnye aspekty terminovedeniya». Pyatigorsk, 2011. $132 \mathrm{~s}$. 
22. Gorbunova N.N. Osnovnye kharakteristiki angloyazychnoi terminosistemy sfery menedzhmenta i ee tematicheskaya stratifikatsiya // Vestnik Pyatigorskogo gosudarstvennogo lingvisticheskogo universiteta. 2014. № 2. S. 76-83.

23. Latu M.N., Alimuradov O.A. K voprosu ob universal'nykh i individual'nykh kharakteristikakh terminosistem (na materiale angloyazychnoi voenno-istoricheskoi terminologii) // Yazyk. Tekst. Diskurs. 2008. № 6. S. 250-255.

24. Razduev A.V. Diskurs sfery nanotekhnologii kak vid nauchnogo diskursa (na materiale sovremennogo angliiskogo yazyka) // Vestnik Chelyabinskogo gosudarstvennogo universiteta. 2013. № 37 (328). S. 52-55.

25. Ivina L.V. Lingvo-kognitivnye osnovy analiza otraslevykh terminosistem (na primere angloyazychnoi terminologii venchurnogo finansirovaniya): uchebno-metodicheskoe posobie. M.: Akademicheskii proekt, 2003. 304 s.

26. Alikaev R.S., Chikhradze A.M. O sushchnostnykh kharakteristikakh definitsii, ponyatiya i termina // Vestnik KabardinoBalkarskogo gosudarstvennogo universiteta. 2000. № 4. S. 61-63.

27. Khakieva Z.U. Semanticheskie i strukturnye osobennosti angloyazychnoi terminologii: sovremennoe sostoyanie i dinamika razvitiya // Yazyk i mental'nost' Ser. «Slavyanskii mir». SPb., 2010. S. 344-351.

28. Razduev A.V. Sravnitel'no-sopostavitel'nyi analiz semantiki, struktury i dinamiki russkogo i angliiskogo pod"yazykov sfery nanotekhnologii // Vestnik Chelyabinskogo gosudarstvennogo universiteta. 2011. № 24. S. 167-170.

29. Kozhevatova D.S., Alimuradov O.A., Razduev A.V. Nekotorye strukturno-slovoobrazovatel'nye modeli angloyazychnoi yuridicheskoi terminologii // Aktual'nye problemy filologii i pedagogicheskoi lingvistiki. 2015. № 4 (20). S. 44 -55.

30. Akaeva Kh.A., Bugaenko N.P., Dokuto B.B., Zhulikov E.V. Voprosu o vozmozhnykh parametrakh strukturnogo i semanticheskogo opisaniya terminologicheskikh sistem: vnutriyazykovoi i mezh"yazykovoi aspekty // Vestnik Pyatigorskogo gosudarstvennogo lingvisticheskogo universiteta. 2013. № 2. S. 68-76.

31. Alimuradov O.A., Gorbunova N.N. Osnovnye sintaksicheskie slovoobrazovatel'nye modeli, realizuemye v angloyazychnoi terminologii menedzhmenta // Izvestiya vysshikh uchebnykh zavedenii. Seriya: Gumanitarnye nauki. 2014 . T. 5 . № 2. S. 95-101.

32. Gorbunova N.N., Alimuradov O.A. Tematicheskie, strukturno-slovoobrazovatel'nye i semanticheskie osobennosti angloyazychnoi terminologii sfery menedzhmenta // Borodin P.A., Gorbunova N.N., Alimuradov O.A. i dr. Sovremennoe sostoyanie i perspektivnye vektory razvitiya filologii, lingvistiki, yazykoznaniya i kommunikativistiki: v 3 t. / Pod nauch. red. O.P. Chigishevoi. Rostov-na-Donu, 2014. S. 30-64.

33. Vinogradov V.A. Vsegda li sistema sistemna? // Sistema i urovni yazyka. M.: Nauka, 1969. S. 249-259.

34. Reformatskii A.A. Termin kak chlen leksicheskoi sistemy yazyka // Problemy strukturnoi lingvistiki. M.: Nauka, 1968.343 s.

35. Klimovitskii Ya.A. Termin i obuslovlennost' opredeleniya ponyatiya v sisteme // Problematika opredelenii terminov v slovaryakh raznykh tipov. L.: Nauka, 1976. S. 107-114.

36. Latu M.N. Motivatsiya termina i definitsiya: sistema korrelyatsii // Scientific Review. Proceedings of the international scientific conference. 2015. S. 280-287.

37. Alimuradov O.A., Latu M.N., Razduev A.V. Osobennosti struktury i funktsionirovaniya otraslevykh terminosistem: na primere terminosistemy nanotekhnologii. 2-e izd., ispr. i dop. Pyatigorsk, 2012.128 s.

38. Shelov S.D. Termin. Terminologichnost'. Terminologicheskie opredeleniya. Seriya: Filologicheskie issledovaniya. SPb.: Filol. fakul'tet SPbGU, 2003. $280 \mathrm{~s}$.

39. Different types of stars in the Universe. [Elektronnyi resurs] URL: https://owlcation.com/stem/Different-Types-of-Starsin-the-Universe (data obrashcheniya: 10.09.2016).

40. Online Etymology Dictionary. [Elektronnyi resurs] URL: http://www.etymonline.com/ (data obrashcheniya: 01.09.2016).

41. Nekrasova T.V. Sistemnost' organizatsii terminologicheskikh edinits v sfere professional'noi kommunikatsii // Vestnik Bashkirskogo universiteta. 2007. Vyp. 4. T. 12. S. 115-118.

42. Kandelaki T.L. Znacheniya terminov i sistemy znachenii nauchno-tekhnicheskikh terminologii // Problemy yazyka nauki i tekhniki. M., 1977. S. 12-92.

43. Tolikina E.N. Nekotorye lingvisticheskie problemy izucheniya termina. M.: Nauka, 1984. $254 \mathrm{~s}$.

44. Supernovae. [Elektronnyi resurs] URL: http://hyperphysics.phy-astr.gsu.edu/hbase/astro/snovcn.html (data obrashcheniya: 10.09.2016).

45. Makarikhina O.A. Analiz i modelirovanie ponyatiinoi struktury terminov sotsial'no-gumanitarnykh nauk (na primere termina «etnos»): Avtoref. diss. ... kand. filos. nauk. Nizhnii Novgorod, 2007. 24 s.

46. Latu M.N. Nominatsiya v razvivayushchikhsya terminosistemakh. Pyatigorsk: SNEG, 2015. $192 \mathrm{~s}$.

47. Star constellations. [Elektronnyi resurs] URL: http://www.solarsystemquick.com/universe/star-constellations.htm (data obrashcheniya: 10.09.2016).

48. Pronina R.F. Perevod angliiskoi nauchno-tekhnicheskoi literatury: ucheb. posobie dlya vtuzov. 3-e izd., ispr. i dop. M.: Vyssh. shk., 1986. $175 \mathrm{~s}$.

49. The stars. The Center for Planetary Science. [Elektronnyi resurs] URL: http://planetary-science.org/astronomy/the-stars/ (data obrashcheniya: 10.09.2016).

50. Tsitkina F.A. Terminologiya i perevod: (K osnovam sopostavitel'nogo ter-minovedeniya). L'vov: Vishcha shkola, Izd-vo pri L'vov. gos. un-te, 1988. $162 \mathrm{~s}$.

51. Array. Webster's Revised Unabridged Dictionary. [Elektronnyi resurs] URL: http://biblehub.com/topical/a/array.htm (data obrashcheniya: 10.09.2016).

52. Novoselov M.M. Logika abstraktsii (metodologicheskii analiz). M., 2000. Ch. I. $191 \mathrm{s.}$

53. Bugorskaya N.V. Eshche raz o tochnosti termina // Sibirskii filologicheskii zhurnal. 2008. № 3. S. 211-219.

54. Kononovich E.V., Moroz V.I. Obshchii kurs astronomii: uchebnoe posobie / Pod red. V.V. Ivanova. M.: Editorial URSS, 2004. $544 \mathrm{~s}$.

55. Latu M.N. Angloyazychnaya voennaya terminologiya v ee istoricheskom razvitii: strukturno-semanticheskii i kognitivnofreimovyi aspekty: Diss. ... kand. filol. nauk. Rostov-na-Donu, 2009. 222 s.

56. Latu M.N., Razduev A.V. Prichiny i modeli vozniknoveniya sinonimii u terminov v sfere fiksatsii // Vestnik Pyatigorskogo gosudarstvennogo lingvisticheskogo universiteta. 2011. № 2. S. 142-145. 


\section{Филология: научные исследования 4(24) • 2016}

57. Razduev A.V. Sovremennyi angliiskii pod"yazyk nanotekhnologii: strukturno-semanticheskaya, kognitivno-freimovaya i leksikograficheskaya modeli: Diss. ... kand. filol. nauk. Pyatigorsk, 2013. 242 s.

58. Alimuradov O.A., Latu M.N. Osobennosti modelirovaniya semantiki terminoedinits. terminologicheskie oppozitsii (na materiale angloyazychnoi voennoi terminologii) // Vestnik Irkutskogo gosudarstvennogo lingvisticheskogo universiteta. 2010. № 3. S. 6-15.

59. Planet. Dictionary.com. [Elektronnyi resurs] URL: http://www.dictionary.com/browse/planet (data obrashcheniya: 01.09.2016).

60. Averbukh K.Ya. Terminologicheskaya variantnost'; teoreticheskie i prikladnye aspekty // Voprosy yazykoznaniya. 1986. № 6. S. 38-49.

61. Temmerman R. Towards New Ways of Terminology Description. The Sociocognitive approach. Amsterdam, 2000.258 p.

62. Picht H., Draskau J. Terminology: An Introduction. Copenhagen, 1985. 255 p.

63. Ridpath I. A Dictionary of Astronomy. Oxford: Oxford University Press, 1997. 544 p.

64. Kapanadze L.A. O ponyatiyakh «termin» i «terminologiya»// Razvitie leksiki sovremennogo russkogo yazyka. M., 1965. S. 75-86.

65. Reformatskii A.A. Mysli o terminologii // Sovremennye problemy russkoi terminologii. M., 1986. S. 163-198.

66. Prokhorova V.N. Semantika termina // Vestnik Mosk. un-ta. Ser. 9. Filologiya. 1981. № 3. S. 24-25. 